training after myocardial infarction. Circulation 37:192, 1968.

36. Varnauskas E, Bergman H, Houk P, Bjorntorp P: Haemodynamic effects of physical training in coronary patients. Lancet 2:8, 1966.

37. Winters WG, Leaman DM, Anderson RA: The effect of exercise on intrinsic myocardial performance. Circulation 48:50, 1973.

38. Whitsett TL, Naughton J: The effect of exercise on systolic time intervals in sedentary and active individuals and rehabilitated patients with heart disease. Am J Cardiol 27:352, 1971.

\title{
The effect of dobutamine on exercise performance in patients with symptomatic ischemic heart disease
}

\begin{abstract}
The effect of dobutamine on exercise performance was assessed in 20 patients with ischemic heart disease (CAD) and a positive stress test. These patients had a wide range of resting left ventricular ejection fraction (range $22 \%$ to $69 \%$, mean $42 \%$ ). Each patient entered a double-blind crossover study in which two identical exercise radionuclide ventriculograms were performed in patients on dobutamine, $5 \mu \mathrm{g} / \mathrm{kg} / \mathrm{min}$ intravenously, or placebo. Dobutamine increased resting left ventricular ejection fraction. Although ejection fraction fell with dobutamine during submaximal exercise, it remained higher than with placebo. At peak exercise, ejection fraction fell to the same level on dobutamine as with placebo. Dobutamine diminished exercise time and time to ischemia while peak pressure-rate product was unchanged. Four of 20 patients developed complex ventricular premature beats, all while on dobutamine. Although useful when administered to resting patients with acute left ventricular failure, dobutamine's effects may be deleterious in exercising patients with chronic ischemic heart disease. (AM HEART J 107:81, 1984.)
\end{abstract}

Mark A. Rabinovitch, M.D., Victor Kalff, M.D., William Chan, M.D., Anthony Schork, Ph.D., Milton D. Gross, M.D., Robert A. Vogel, M.D., James H. Thrall, M.D., and Bertram Pitt, M.D. Ann Arbor, Mich.

Dobutamine is a positive inotropic agent with a predominant action on beta-1-adrenergic receptors and a relatively weak chronotropic effect. ${ }^{1}$ It has found wide use in patients with ischemic and nonischemic ventricular failure. ${ }^{2-5}$ Dobutamine's use in patients with acute ischemic left ventricular failure is supported by experimental studies showing that it may maintain or improve coronary blood flow to

From the Divisions of Cardiology and Nuclear Medicine, Department of Internal Medicine, University of Michigan Medical Center, and The Veterans Administration Medical Center.

Supported by a grant from Eli Lilly \& Company, by a Canadian Heart Foundation Research Fellowship (Dr. Rabinovitch), and by an Australian Heart Foundation Travel Grant (Dr. Kalff).

Received for publication March 1, 1982; revision received Aug. 2, 1982; accepted Aug. 9, 1982.

Reprint requests: Mark A. Rabinovitch, M.D., Department of Cardiology, Montreal General Hospital, Room 5590-1650 Cedar Ave., Montreal, Quebec H3G 1A4, Canada. ischemic or potentially ischemic areas of myocardium. . $^{7}$

It would also be of interest to know what effects dobutamine has on left ventricular performance during exercise in patients with ischemic heart disease. For example, if dobutamine improves the myocardial oxygen supply-demand ratio in this setting, then its intermittent infusion could be useful in conjunction with exercise in postmyocardial infarction patients undergoing cardiac rehabilitation. ${ }^{9}$ The present study was therefore designed to assess dobutamine's effect on exercise performance in a group of patients with chronic ischemic heart disease (CAD) and a wide range of resting left ventricular function.

\section{METHODS}

Patients. Twenty ambulatory patients with ischemic heart disease were studied after giving informed consent. 


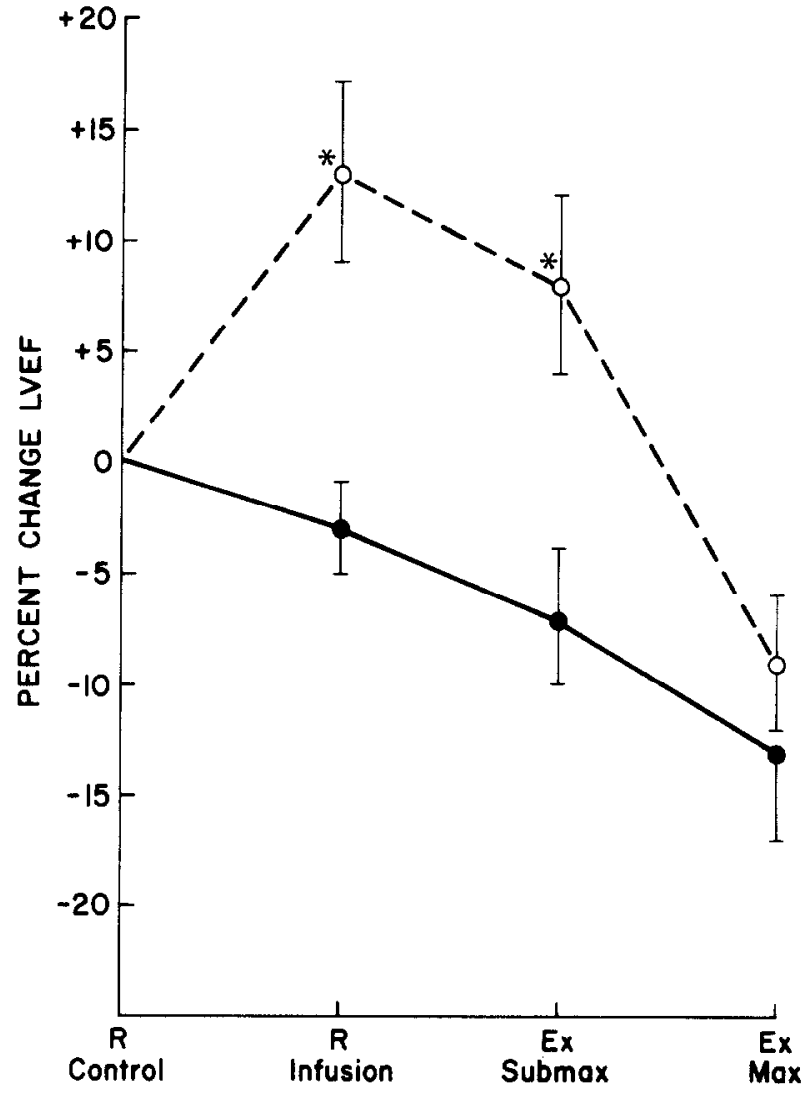

Fig. 1. Illustration of the effect of dobutamine on the ejection fraction at rest and during exercise. The solid lines represent the response to placebo, the dashed lines the response to dobutamine. $L V E F=$ left ventricular ejection fraction; $R=$ resting; $E x \quad S u b \max =$ submaximal exercise, $E x M a x=$ maximal exercise. ${ }^{*} p<0.01$.

There were 18 men and two women and their mean age was 56 years (range 34 to 81 ). Coronary artery disease was proved in 17 cases by catheterization, and presumed in two with classic angina and segmental wall motion defects on exercise radionuclide ventriculography and in one with angina pectoris following two documented myocardial infarctions. Of the catheterization-proved cases, 10 had triple-vessel disease, six had double-vessel disease, and one had single-vessel disease. Eighteen patients had classic angina pectoris and 13 had well-documented previous myocardial infarctions. All 20 had exercise-induced ischemia as revealed by exercise ECG and/or rest-exercise radionuclide ventriculography. No patient was studied within 6 weeks of a myocardial infarction and patients with significant valvular disease were excluded. All patients were in functional class II or III of the New York Heart Association, and none had clinically uncompensated congestive failure at the time of the study.

Testing. All beta-adrenergic-blocking agents and other sympatholytics were discontinued at least 72 hours prior to testing and all long-acting nitrates were stopped at least
Table I. Resting hemodynamics of study group

\begin{tabular}{llll}
\hline & $E F$ & $H R$ & AP systolic \\
\hline Mean \pm SD & $42 \pm 15$ & $77 \pm 14$ & $133 \pm 16$ \\
Range & $22-68$ & $55-102$ & $110-165$ \\
\hline
\end{tabular}

Abbreviations: $\mathrm{EF}=$ ejection fraction; $\mathrm{HR}=$ heart rate; $\mathrm{AP}=$ arterial pres sure.

12 hours beforehand. Two intravenous solutions, one containing placebo (dextrose and water) and the other containing dobutamine $(5 \mu \mathrm{g} / \mathrm{kg} / \mathrm{min}$ infusion via Harvard pump), were prepared by the hospital pharmacy and labeled randomly as solutions A and B. Each patient then underwent supine, multiple, gated rest-exercise radionuclide ventriculography. ${ }^{1 "}$ First, baseline resting images were obtained in the left anterior oblique (LAO) and 10-degree right anterior oblique (RAO) projections. Then infusion of solution $\mathrm{A}$ was commenced and 3 minutes later repeat $\mathrm{LAO}$ and 10-degree RAO images were obtained. While the infusion of solution A continued, each patient performed a symptom-limited exercise protocol consisting of 4-minute stages at standardized incremental work loads. Images were obtained at each level of exercise in the LAO view. A final 10-degree RAO image was acquired at a submaximal exercise load (25 watt-seconds less than peak). After at least 1 hour of recuperation, each patient underwent identical rest-exercise radionuclide ventriculography, but with solution B instead of A. Heart rate, blood pressure, and the CM 5 ECG lead were monitored throughout each study.

Data analysis. The following exercise parameters were measured in each patient for both the dobutamine and placebo exercise periods: (1) peak work load completed, (2) exercise time, (3) time to angina, (4) time to significant ST depression defined as $\geq 1 \mathrm{~mm}$ of horizontal or downsloping depression below baseline in the absence of digitalis therapy, (5) time to ischemia defined as the time to onset of angina or ST depression, whichever came first, and (6) development of significant ventricular ectopy $(>10$ ectopics/min, $\geq 2$ foci, couplets, ventricular tachycardia).

The following hemodynamic and ventriculographic parameters were measured in each patient for both the dobutamine and placebo exercise periods: (1) heart rate, (2) systemic arterial pressure, (3) pressure-rate product defined as systolic pressure $x$ heart rate/100, (4) left ventricular ejection fraction determined by computerassisted analysis of the left ventricular time-activity curve with the use of commercially available software $\left(\mathrm{A}^{2} \mathrm{Medi}\right.$ cal Data Systems), (5) count-based end-diastolic and end-systolic relative volumes, ${ }^{11}$ and (6) segmental wall motion analysis. Briefly, decay and background-corrected count rates were calculated from the left ventricular region of interest of the end-diastolic and end-systolic frames for each LAO image. Taking the resting baseline count rate to be $100 \%$, the percentages of change in end-diastolic and end-systolic count rates were calculated for the dobutamine and placebo infusions and for each 
Table II. Hemodynamic effects of dobutamine (\% change from control)

\begin{tabular}{|c|c|c|c|c|c|}
\hline & & $H R(b p m)$ & AP systolic (mm Hg) & $P R P$ & $E F$ \\
\hline \multirow[t]{3}{*}{ Rest } & D & $+6 \pm 2$ & $+9.3 \pm 2$ & $+17 \pm 2$ & $+13 \pm 4$ \\
\hline & PL & $-0.5 \pm 1$ & $+1.3 \pm 2$ & $+1.5 \pm 2$ & $-3 \pm 2$ \\
\hline & $p^{*}$ & $<0.01$ & $<0.01$ & $<0.01$ & $<0.01$ \\
\hline \multirow[t]{3}{*}{ Submaximal exercise } & D & $+38 \pm 6$ & $+18 \pm 3$ & $+63 \pm 9$ & $+8 \pm 4$ \\
\hline & PL & $+31 \doteq 4$ & $+16 \pm 3$ & $+57 \pm 7$ & $-7 \pm 3$ \\
\hline & $p$ & NS & NS & NS & $<0.01$ \\
\hline \multirow[t]{3}{*}{ Maximal exercise } & D & $+55 \pm 7$ & $+21 \pm 3$ & $+86 \pm 10$ & $-9 \pm 3$ \\
\hline & PL & $+56 \pm 5$ & $+23 \pm 3$ & $+90 \pm 9$ & $-13+4$ \\
\hline & $p$ & NS & NS & NS & NS \\
\hline
\end{tabular}

Abbreviations: $\mathrm{D}=$ dobutamine; $\mathrm{PL}=$ placebo; $\mathrm{HR}=$ heart rate; $\mathrm{AP}=$ systemic arterial pressure; $\mathrm{PRP}=$ pressure-rate product $(\mathrm{HR} \times \mathrm{AP}$ systolic $/ 100)$; $\mathrm{EF}=$ ejection fraction. The change in $\mathrm{EF}$ is expressed as a $\%$ from control (e.g., EF $30 \% \rightarrow 50 \%$ gives a $67 \%$ change).

*Bonferroni experimentwise $p$ value.

exercise level. These were expressed as percentage of change in end-diastolic volume and percentage of change in end-systolic volume. The anterobasal, anterolateral, and apical segments were analyzed from the RAO projection and the inferoapical, posterolateral, and posterobasal segments were assessed from the LAO projection. The septal segment was excluded from analysis because of poor reproducibility of subjective analysis and the diaphragmatic segment was excluded because of frequent right ventricular overlap. Wall motion was visually judged to be either hyperkinetic $(4+)$, normal $(3+)$, mildly hypokinetic $(2+)$, severely hypokinetic $(1+)$, akinetic $(0)$, or dyskinetic $(-1)$. Worsening of motion in any wall segment was defined as a reduction of one or more grades compared to resting baseline while improvement was defined as an increase of one or more grades compared to resting baseline.

Statistical analysis. Absolute resting hemodynamics of the study group are expressed as the mean \pm one standard deviation (SD). All other data are expressed as the mean \pm standard error of the mean (SEM). Student's $t$ test for paired data was used to determine the significance of the differences between all exercise, hemodynamic, and ventriculographic parameters during placebo and dobutamine administration. Hemodynamic and ventriculographic parameters were compared at rest, submaximal exercise (one stage below peak), and maximal exercise. Experimentwise, $\alpha$ errors using Bonferroni's method were used to assess significance for each exercise condition (rest, submaximal, and maximal).

\section{RESULTS}

Hemodynamics. The baseline resting hemodynamics of the study groups are listed in Table I. The hemodynamic effects of dobutamine at rest are summarized in Table II. Dobutamine increased resting heart rate, systolic blood pressure, pressure-rate product, and resting left ventricular ejection fraction. Two patients had a decrease in left ventricular ejection fraction on dobutamine infusion before exercise. In one patient, the ejection fraction fell from $68 \%$ to $54 \%$ with the appearance of a new wall motion abnormality. The other patient had a decrease in left ventricular ejection fraction from $30 \%$ to $22 \%$ on dobutamine before exercise.

Twelve of the 20 patients were able to perform an intermediate (submaximal) level of exercise prior to the development of symptoms. The hemodynamic effects of dobutamine during submaximal exercise in these 12 patients are shown in Table II. The increases in heart rate, systolic arterial pressure, and pressure-rate prdouct were similar on dobutamine and placebo. Concurrently, left ventricular ejection fraction remained higher while patients were on dobutamine. The hemodynamic effects of dobutamine during maximal exercise for the study population are also shown in Table II. Peak heart rate, systolic arterial pressure, and pressure-rate product increased by approximately the same amount on dobutamine and placebo while the fall in left ventricular ejection fraction was similar for dobutamine and placebo.

Comparison of the ejection fraction responses on dobutamine and placebo is depicted in Fig. 1. Ejection fraction rose with dobutamine at rest. Although ejection fraction fell with dobutamine during submaximal exercise, it remained higher than with placebo. At peak exercise, ejection fraction fell to the same level as with placebo. Dobutamine caused improved motion in a notable percentage of wall segments at rest and submaximal exercise compared with placebo. By peak exercise, few improved segments remained on either infusion. Approximately the same percentage of segments worsened during exercise with dobutamine and placebo. Although relative end-diastolic and end-systolic volume tended to be smaller on dobutamine than on placebo, the differences were not statistically significant. 
Table III. Effects of dobutamine on exercise tolerance

\begin{tabular}{lcccc}
$\begin{array}{c}\text { Ex time } \\
\text { (min) }\end{array}$ & $\begin{array}{c}\text { Peak work } \\
\text { load }(W-S)\end{array}$ & $\begin{array}{l}\text { Time to } \\
\text { angina } \\
\text { (min) }\end{array}$ & $\begin{array}{c}\text { Time to } \\
\text { ischemia } \\
\text { (min) }\end{array}$ \\
\hline D & $6.7 \pm 0.8$ & $51 \pm 6$ & $4.3 \pm 0.7$ & $3.8 \pm 0.7$ \\
Pl & $8.7 \pm 1.1$ & $63 \pm 7$ & $6.2 \pm 1.1$ & $5.5 \pm 1.1$ \\
$p^{*}$ & NS & $<0.05$ & NS & NS \\
\hline
\end{tabular}

Abbreviations: $\mathrm{Ex}=$ exercise; $\min =$ minutes; $\mathrm{W}-\mathrm{S}=$ watt-seconds; other abbreviations as in Table II.

${ }^{+}$Bonferroni experimentwise $p$ value.

Exercise performance. Dobutamine's effects on measurements of exercise tolerance are summarized in Table III. While dobutamine produced a curtailment in total exercise time, time to angina, and time to ischemia, only a reduction in peak work load achieved a statistically significant reduction. Exercise time, peak work load achieved, and time to ischemia were the same or shorter on doubtamine in 19 out of the 20 patients. Only one patient demonstrated improved exercise tolerance on dobutamine. Although no patient in this series sustained ventricular tachycardia, four developed lower grades of ventricular ectopy on dobutamine which did not appear on placebo.

\section{DISCUSSION}

Despite a decade of investigation, controversy continues to surround the use of dobutamine in the setting of myocardial ischemia. Tuttle and Mills ${ }^{1}$ synthesized dobutamine in an attempt to minimize isoproterenol's potent chronotropic, arrhythmogenic, and peripheral vascular effects. They documented that these properties, which made the use of isoproterenol hazardous in the context of myocardial ischemia, were greatly attenuated with dobutamine. ${ }^{1}$ They postulated that dobutamine's ability to increase myocardial oxygen consumption by increasing contractility would be offset by a reduction in ventricular volume and thus wall tension. They also predicted that because of its strong inotropic action and attenuated chronotropic and beta-2 stimulatory effects, dobutamine should actually improve coronary blood flow to an ischemic region and limit the extent of infarction. This hypothesis has been tested in several animal models and the results were found to be variable, in part depending upon the degree of tachycardia induced by dobutamine. ${ }^{6,12-14}$

Previous studies. Results in patients with ischemic heart disease have also been variable. Gillespie et al. ${ }^{2}$ administered dobutamine in doses of 1 to $40 \mu \mathrm{g} /$ $\mathrm{kg} / \mathrm{min}$ for 24 hours, so as to avoid an excessive increase in heart rate, in 16 patients with evolving acute myocardial infarction and impaired left ventricular function. Dobutamine improved left ventricular performance without evoking myocardial ischemia or arrhythmias. Recently, the effects of dobutamine in chronic ischemic heart disease have been explored. In doses of 2.5 to $10 \mu \mathrm{g} / \mathrm{kg} / \mathrm{min}$, Bendersky et al. ${ }^{15}$ found that dobutamine could improve left ventricular function without evoking myocardial ischemia in seven of eight patients with chronic ischemic heart failure. Pozen et al. ${ }^{16}$ administered dobutamine to 18 patients with ischemic heart disease and a history of congestive heart failure by using a protocol of incremental infusion of dobutamine from 2.5 to $15 \mu \mathrm{g} / \mathrm{kg} / \mathrm{min} .{ }^{16}$ Four adverse metabolic responders were identified on the basis of lactate extraction, three of whom developed angina pectoris. It is probable that any salutary effect of dobutamine was overbalanced by its oxygen-wasting effects in these four patients.

Present study. The present study demonstrates that dobutamine reduces exercise capacity in patients with ischemic heart disease over a wide range of resting left ventricular function. The fact that the time to exercise-induced ischemia was shorter for patients on dobutamine while peak pressure-rate product was the same suggests that a critical level of myocardial oxygen consumption was reached earlier while patients were on dobutamine.

The patients did, however, maintain a significantly higher left ventricular ejection fraction during submaximal exercise on dobutamine compared with placebo. On the surface, this result appears at odds with the reduced exercise capacity of patients on dobutamine. The analysis of segmental left ventricular function, albeit qualitative, provides an explanation. At rest, dobutamine improved a large number of myocardial segments which were either hypokinetic or normokinetic. However, during submaximal and maximal exercise, there were as many deteriorated segments on dobutamine compared with placebo. Therefore, the higher left ventricular ejection fraction at submaximal exercise on dobutamine probably reflected better function of nonischemic segments rather than any reduction in the mass of ischemic myocardium. Furthermore, the study group did not have a significant reduction in left ventricular volumes on dobutamine at rest or during submaximal exercise. It is, therefore, likely that any slight reduction in wall tension that might have occurred secondary to dobutamine was overshadowed by its oxygen-wasting property.

Mechanisms. Three factors may have contributed to the unfavorable outcome of dobutamine treatment in the present study. First, despite a relatively 
low dose of dobutamine of $5 \mu \mathrm{g} / \mathrm{kg} / \mathrm{min}$ used in the present study, resting heart rate rose significantly. This unexpected rise in resting heart rate could not be attributed to a hyperadrenergic state secondary to beta blocker withdrawal. There were no significant differences in the hemodynamic response (heart rate, systolic arterial pressure, and left ventricular ejection fraction) in the five patients in whom beta blockers had been withdrawn prior to the study and the 15 patients who had not been on beta-adrenergic blockers. Second, most of the patients in the present study who were catheterized had multivessel disease (16 of 17) and 10 of $17 \mathrm{had}$ triple-vessel disease. The presence of diffuse myocardial ischemia, as shown in an experimental study by Vatner et al., ${ }^{17}$ would be expected to block improvement in myocardial contractility and, as a result, there would be little, if any, improvement in coronary perfusion in the face of increased myocardial oxygen demands resulting from an increase in heart rate and/or wall tension. Third, in the present study, mild coronary artery stenoses were present in addition to high-grade lesions in several patients. It has recently been shown that dobutamine, in addition to other beta-receptor stimulators, can produce a reduction in coronary perfusion pressure distal to such mild stenoses resulting in a maldistribution of distal coronary blood flow away from the subendocardium. ${ }^{18}$

Conclusions. This study indicates that dobutamine may have adverse effects on exercise performance in patients with reversibly ischemic myocardium. However, as suggested by the study of Bendersky et al, ${ }^{15}$ dobutamine might be beneficial in patients with compromised left ventricular function but little or no remaining reversibly ischemic myocardium $^{15}$. The present study suggests caution in the use of any inotropic agent in patients with chronic ischemic heart disease. Before an inotropic agent can be recommended for use in such patients, there should be clear demonstration that the balance between myocardial oxygen supply and demand, as evidenced by exercise tolerance, is improved. An improvement in global left ventricular performance, as measured by left ventricular ejection fraction, may not reflect the effect of the agent on ischemic or potentially ischemic areas of myocardium.

We thank Ms. Kathleen Worthington for her technical assistance and Ms. Diane Vecellio for preparation of this manuscript. We are grateful to Mary Ellen Henderson, Pharm. D., for preparation and randomizaton of the intravenous solutions.

\section{REFERENCES}

1. Tuttle RR, Mills J: Dobutamine. Development of a new catecholamine to selectively increase cardiac contractility. Circ Res 36:185, 1975.
2. Gillespie TA, Ambos HD, Sobel BE, Roberts R: Effects of dobutamine in patients with acute myocardial infarction. Am J Cardiol 39:588, 1977.

3. Akhtar N, Mikulic E, Cohn JN, Chaudhry MH: Hemodynamic effect of dobutamine in patients with severe heart failure. Am J Cardiol 36:202, 1975.

4. Loeb HS, Bredakis J, Gunnar RM: Superiority of dobutamine over dopamine for augmentation of cardiac output in patients with chronic low output cardiac failure. Circulation 55:375, 1977.

5. Leier CV, Heban PT, Huss P, Bush CA, Lewis RP: Comparative systemic and regional hemodynamic effects of dopamine and dohutamine in patients with cardiomyopathic heart failure. Circulation 58:466, 1978.

6. Tuttle RR, Pollock GD, Todd G, MacDonald B, Tust R, Dusenberry $\mathrm{W}$ : The effect of dobutamine on cardiac oxygen balance, regional blood flow and infarction severity after coronary artery narrowing in dogs. Circ Res 41:357, 1977.

7. Sonnenblick EH, Frishman WH, LeJemtel TH: Dobutamine: A new synthetic cardioactive sympathetic amine. N Engl J Med 300:17, 1976.

8. Vasu MA, O'Keefe DD, Kapellakis GZ, et al: Myocardial oxygen consumption: Effects of epinephrine, isoproterenol, dopamine, norepinephrine and dobutamine. Am J Physiol 235: $\mathrm{H} 237,1978$.

9. Liang C, Tuttle RR, Hood WB Jr, Haralambos G: Conditioning effects of chronic infusions of dobutamine: Comparison with exercise training. J Clin Invest 64:613, 1979.

10. Brady TJ, Thrall JH, Clare JM, Rogers WL, Lo K, Pitt B: Exercise radionuclide ventriculography: Practical considerations and sensitivity of coronary artery disease detection. Radiology 132:697, 1979.

11. Sorensen SG, Ritchie JL, Caldwell JH, Hamilton GW, Kennedy JW: Serial exercise radionuclide angiography: Validation of count-derived changes in cardiac output and quantitation of maximal exercise ventricular volume change after nitroglycerin and propranolol in normal men. Circulation 61:600, 1980 .

12. Liang C, Yi JM, Sherman LG, Black J, Gavras H, Hood WB Jr: Dobutamine infusion in conscious dogs with and without acute myocardial infarction. Effects on systemic hemodynamics, myocardial blood flow and infarct size. Circ Res 49:170, 1981.

13. Willerson JT, Hutton I, Watson JT, Platt MR, Templeton $\mathrm{GH}$ : Influence of dobutamine on regional myocardial blood flow and ventricular performance during acute and chronic myocardial ischemia in dogs. Circulation 53:828, 1976.

14. Vatner SF, Baig $H$ : Importance of heart rate in determining the effects of sympathomimetic amines on regional myocardial function and blood flow in conscious dogs with acute myocardial ischemia. Circ Res 45:793, 1979.

15. Bendersky R, Chatterjee K, Parmley WW, Brundage BH, Ports TA: Dobutamine in chronic ischemic heart failure: Alterations in left ventricular function and coronary hemodynamics. Am J Cardiol 48:554, 1981.

16. Pozen RG, DiBianco R, Katz RJ, Bortz R, Myerburg RJ, Fletcher RD: Myocardial metabolic and hemodynamic effects of dobutamine in heart failure complicating coronary artery disease. Circulation 63:1279, 1981.

17. Vatner SF, McRitchie RJ, Maroko PR, Patrick TA, Braunwald E: Effects of catecholamines, exercise and nitroglycerin on the normal and ischemic myocardium in conscious dogs. J Clin Invest 54:563, 1974.

18. Warltier DC, Zyvoloski M, Gross GJ, Hardman HF, Brooks HL: Redistribution of myocardial blood flow distal to a dynamic coronary arterial stenosis by sympathomimetic amines. Comparison of dopamine, dobutamine and isoproterenol. Am J Cardiol 48:269, 1981. 